\title{
The development of the public and professional policy committee
}

\author{
Ségolène Aymé ${ }^{1}$ and Martina C Cornel ${ }^{2}$ \\ European Journal of Human Genetics (2017) 25, S29-S32; doi:10.1038/ejhg.2017.160
}

The Public and Professional Policy Committee (PPPC) of the ESHG was established in 1998, and was preceded by the Society's Ethics Committee, set up in 1994 and chaired by Marcus Pembrey. The Ethics Committee had a narrower remit than the PPPC, working primarily on the harmonisation of practice guidelines for human geneticists in Europe.

\section{PART 1: SÉGOLÈNE AYMÉ (FR)}

I was the President of the Society when the PPPC was set up. Its establishment took place in the context of the tremendous advances in molecular technology coming out of the Human Genome Programme. This emergence of genetic technology was accompanied by an increasing concern about the use and misuse of genetic information in society. We felt it was the duty of professionals to anticipate the potential applications of their discoveries, to transfer their knowledge as fast as possible where a benefit could be expected for the community, and to provide guidelines and recommendations to help the less experienced professionals minimise misuse and misinterpretations. I chaired the PPPC during its first 10 years (1998-2007).

The establishment of the committee was heavily influenced by the 1995 WHO publication of a document entitled: 'Guidelines on Ethical Issues on Medical Genetics and the Provision of Genetic Services', written by Dorothy Wertz (ASHG), John Fletcher (ASHG), Kare Berg (ESHG) and Viktor Boulyjenkov (WHO), without any consultation with their respective organisations, nor of any colleagues. Many human geneticits felt that there was an urgent need for a more democratic and transparent process in the issuing of recommendations and to be truly representative of the human genetics community. During his ESHG presidency (1994-1995), Marcus Pembrey was instrumental in pushing successfully in that direction.

The initial terms of reference of the PPPC were:

- To formulate, on behalf of the ESHG, the professional and scientific view on the social, ethical and legal issues that impact on professional practice. The relationship between medical/human geneticists and the public.

- To produce and regularly review ESHG policy statements, guidelines and reports, within the PPPC's Terms of Reference, following a consultation period (where practical) during which ESHG members can comment on draft documents after approval by the ESHG Board. To publish the definitive documents on the ESHG website or, where appropriate, submit them for publication to the peer-reviewed journal.

- To promote the PPPC's views and influence.

- To encourage ESHG representation, whether formal or through individual ESHG members, on key policy-making committees.

- To respond to requests for opinions on reports, guidelines, draft laws, etc. produced by other organisations, and publishing these responses where appropriate. A response may be not to take it further. Keep Executive Board fully informed.

- To respond to publications, reports, legislations or events with press releases and interviews, where appropriate and when the PPPC's policy on the issue is clear.

- To maintain a watching brief on ongoing topics of concern that are agreed with the ESHG Board, and to report back as and when requested by the Board.

- To assist the International Federation of Human Genetics Societies in its production of policy statements, guidelines and reports.

- All published documents have to be approved by the Board.

The PPPC decided immediately that it was not possible to issue sound opinions or recommendations in such a complex and controversial field, without enough resources to organise a wide consultation of the community and prepare well-documented reports. There was an opportunity to apply for European Commission funding, through a COST programme in the field of ethics. Four topics were proposed and accepted:

'Genetic screening: technical and ethical issues, including commercialisation of genetic tests'.

'Genetic testing, insurance and employment: technical, social and ethical issues'.

'Guidelines for the provision of genetic services in Europe'.

'Data storage and DNA banking: quality issues, confidentiality, informed consent'.

The reports were produced by working parties gathering experts from all necessary disciplines, nominated by colleagues from all European countries to ensure balanced cultural and geographical representation. The PPPC prepared in advance the questions for debate at a workshop. Prior to the workshop, all participants received a comprehensive report summarising the state of play on the basis of published articles and reports. The reports were modified after the workshop to include all views expressed, and then sent to all ESHG members for comment. After this round of consultations, the

${ }^{1}$ Institut du Cerveau et de la Moelle Épinière, Centre National de la Recherche Scientifique Unite Mixte de Recherche 7225 , Institut National de la Santé et de la Recherche Médicale U 1127, Université Pierre et Marie Curie-P6 Unite Mixte de Recherche S 1127, Paris, France; ${ }^{2}$ Clinical Genetics \& Amsterdam Public Health Research Institute, VU University Medical Center, Amsterdam, The Netherlands 
documents were adopted by the ESHG Board and published. This approach provided a sound empirical base upon which to develop consensus policies in the field of human genetics and biotechnology, respecting both the state of art and the values in different member states. It is this approach that I used later on to propose policy developments in the field of rare diseases, under the umbrella of the Rare Disease Task Force of the European Commission (2004-2009) and of the European Union Committee of Experts on Rare Diseases (2010-2013).

The methodology used by the PPPC during its first years was right and productive, but required substantial resources. The PPPC failed to obtain a second contract with the EC, as it was perceived as a standing committee of the ESHG, and no longer a research consortium. The methodology was also too slow at a time when technology and societal changes were accelerating. The ESHG wanted to have quicker responses to emerging issues. It was time for a change.

\section{MARTINA C CORNEL (NL)}

After a successful period under Ségolène's leadership, I became the chair of the PPPC in 2007. As Ségolène has said, it is the mission of PPPC to contribute to the responsible translation of advances in human genetics. 'Responsible translation' requires giving attention to the evidence of utility of a genetic test, its ethical and legal aspects, and collaboration with all the different actors involved. Where laboratory scientists develop new technologies, health-care professionals can apply them if patients or citizens demand and accept them and regulatory and governmental agencies allow them and fund them. Discussions and debate are often needed to clarify and attune expectations, to understand sensitivities and to implement new technologies in health care in a way that is appreciated by citizens, patients and professionals alike.

What makes a PPPC publication different from many others is that not only is it reporting on new scientific developments, but the process of the development of the background documents, recommendations and points to be considered implies that discussion with different stakeholders has already taken place. Some recommendations have been developed with other professional societies; many drafts have been posted online and have invited the membership of ESHG and external experts to comment. Often national societies of human genetics have discussed the documents in their own setting, and sometimes endorsed the recommendations.

Two of the most important technological developments on which recommendations were developed are whole genome sequencing in health care' and 'non-invasive prenatal testing', both developments with potentially enormous potential for health care.

Whole-genome sequencing technologies could shorten the diagnostic odyssey, but the disclosure of unsolicited findings poses a challenge for the informed consent procedure. Some unsolicited findings can have a high clinical utility, but not answer the primary question for which the test was undertaken. If a test is asked to find a cause of mental retardation and multiple congenital anomalies, and the result is an inherited cancer syndrome, what is our professional obligation? The recommendations (doi: 10.1038/ejhg.2013.46) include the advice to set up structures for sharing experiences and establish testing guidelines at local, national and international levels. Furthermore, it is preferable to use a targeted approach first.

Non-invasive prenatal testing (NIPT) for aneuploidy is another development that became available in regular health care recently. Recommendations (doi: 10.1038/ejhg.2015.57) were developed together with ASHG. A major advantage of NIPT is its greater accuracy and safety with respect to prenatal screening in comparison with combined testing and subsequent invasive testing (eg, amniocentesis). Implementation of NIPT can lead to a significant reduction of the rate of invasive testing, and thus of procedure-related miscarriages. Commercial providers have already begun expanding their tests to include sex-chromosomal abnormalities and microdeletions. However, multiple false positives may undermine this main achievement. ESHG and ASHG argue for a cautious expansion of the scope of prenatal screening to serious congenital and childhood disorders, only following sound validation studies and a comprehensive evaluation of all relevant aspects.

PPPC is a relatively large committee, with 15 members. These work in smaller working groups, often distributing the topics that need attention. A PPPC member is actively engaged in one or several of the ongoing activities.

\section{COLLABORATION WITH ASHG - BUILDING BRIDGES}

The American Society of Human Genetics has also recognised the need to engage in societal issues, and has set up a Social Issues Committee (SIC). In recent years SIC and PPPC have had contact, which led to the joint recommendations on NIPT. Furthermore, some sessions for conferences were developed together, for instance panel discussions. Besides the SIC and PPPC relationship, 'building bridges' appeared on the agenda at Board level, as, eg, the Tuesday morning session 'ESHG-ASHG Building Bridges Debate: Ethical and Legal Discussions - Past, Present \& Future' at the Copenhagen conference in 2017. 


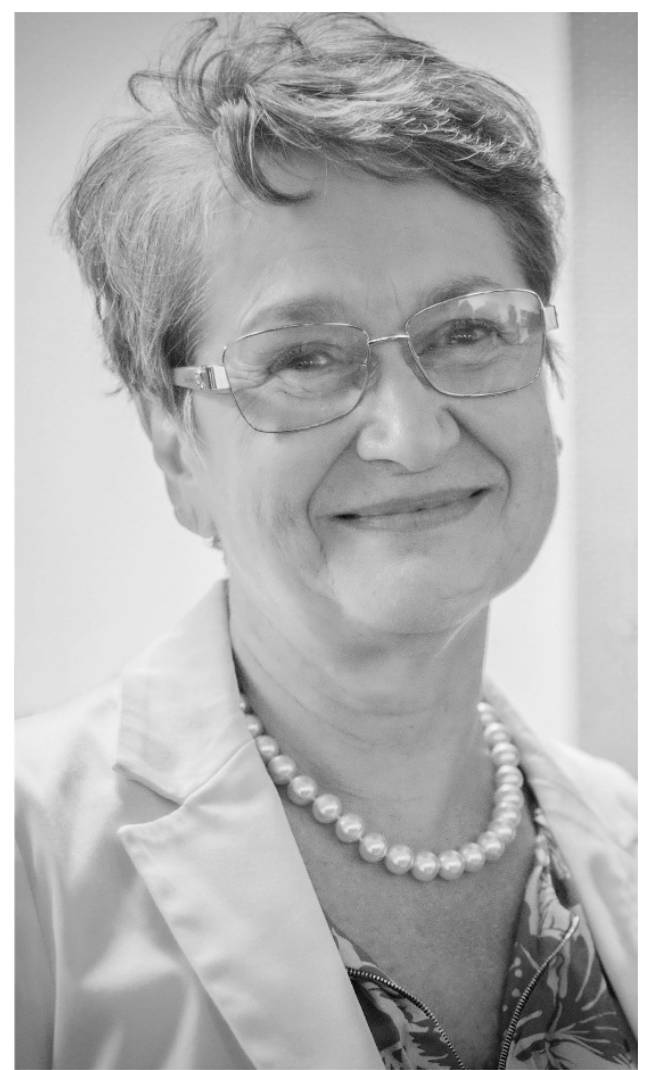

Ségolène Aymé is Emeritus Director of Research at the French Institute of Health and Medical Research (INSERM). She started her career in 1972 as an Assistant Professor in Medical Genetics until she joined the INSERM as a researcher in 1978. She dedicated her professional life to the development of tools and innovative practices to improve the diagnosis and management of genetic and other rare diseases, the access to expert services and the development of appropriate policies at national and international level. She worked on the public health dimension of innovative practices in genetics. She was the president of the ESHG (1996), president of the French Society of Human Genetics (2004-2008) and the first president of the International Federation of Human Genetics Societies (1998-2000). She chaired the Public and Professional Policy Committee of the ESHG (1997-2008) and acted as liaison officer for International affairs (2005-2010). She was the founder of Orphanet in 1997 and its Executive Manager up to 2011. She chaired the EU Committee of Experts on rare Diseases (2010-2013). She also chaired the WHO Topic Advisory Group for Rare Diseases from 2008 to 2016 and managed the scientific secretariat of the International Rare Disease Research Consortium IRDiRC from 2012 to 2015. She acted as section editor for the EJHG, for genetic services, and she founded, in 2006, the Orphanet Journal of Rare Diseases (www.ojrd.com). 


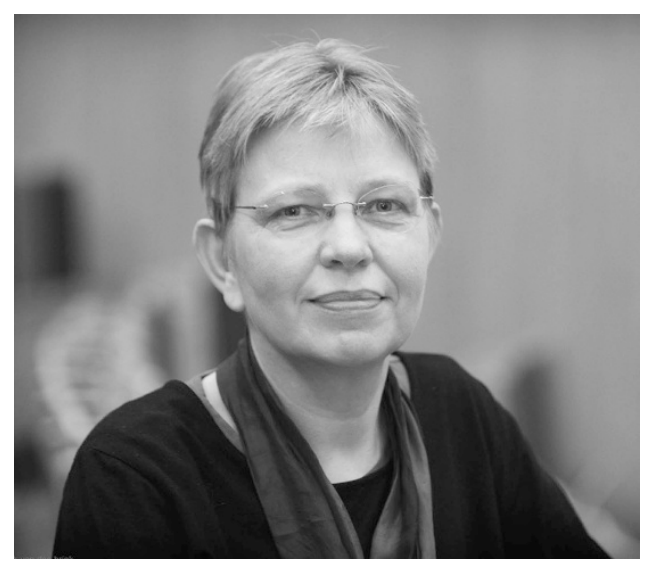

Martina C Cornel, MD, $\mathrm{PhD}(\%, 1959)$ is the professor of community genetics and public health genomics at the VU University Medical Center in Amsterdam. She is a physician and epidemiologist. After 2000, she mainly worked on the responsible implementation of genetic testing and screening. Since 2007, she is the chair of the Public and Professional Policy Committee of the European Society of Human Genetics, that developed among others recommendations on genetic testing in minors, principles for good practice in paediatric biobanks (Hens, 2013), recommendations on whole-genome sequencing in health care (Van El, 2013), recommendations on responsible implementation of NIPT (Dondorp, 2015), and on responsible implementation of carrier testing (Henneman, 2016). Her favourite part of the ESHG meetings are the debates, such as the Building Bridges Sessions with ASHG. She is a member of the Netherlands Health Council and two of its standing committees (Population Screening and Public Health). She is the chair of the Netherlands Program Committee Neonatal Heelprick Screening. She also chaired the debate on developing expert advice on newborn screening in Europe, as part of the EU funded Tender newborn screening (Cornel et al, 2014). During the large-scale funding of the Netherlands Genomics Initiative, she was the principal investigator in the Netherlands Center for Society and Genomics and chair of the Societal Aspects Committee of the Center for Medical Systems Biology. 